Academic Entrepreneurship for Medical and Health Scientists • Academic Entrepreneurship for Medical and Health Sciences

\title{
Does My Invention Already Exist? Conducting a \\ Patent/Prior Art Search
}

\section{Toshitha Kannan ${ }^{1}$, Elliot Stein², D. Mark Maloney ${ }^{3}$}

${ }^{1}$ MS; The Wistar Institute, ${ }^{2}$ MD, MSTR; Pennsylvania Hospital | University of Pennsylvania,

${ }^{3}$ MS, JD; Johns Hopkins University

Published on: Sep 27, 2019

License: Creative Commons Attribution-NonCommercial-NoDerivatives 4.0 International License (CC-BY-NC-ND 4.0). 


\section{Topic Relevance by Timeline}

\section{Summary}

- Patent/prior art searches are an essential step in the process of establishing the novelty of a product or solution.

- Increasing the comprehensiveness of a prior art search enhances the likelihood of success for a new patent because the inventor becomes more aware of the state of the field, can create and perceive distinctions between their invention and existing inventions, and is able to preempt sources of conflict with prior patent literature.

- Publicly available resources are the best place to start a prior art search.

- Follow this mantra-brainstorm, search, retrieve and expand!

- Documentation of all search results is a necessity and may prove essential in later discussions with a patent professional or when filling patent paperwork to demonstrate that a reasonably extensive search was performed.

- Resources from the university can offer counsel. There are almost always people who are trained to be experts in prior art searches and will be more than willing to help out.

\section{Introduction}

There are many ways to describe an academic entrepreneur's experience with patent/prior art searches. One might call them painfully time-consuming, or perhaps a test of one's patience and organization skills. Regardless, they are a crucial step. In layman's terms, prior art refers to any publicly available description, reference, or physical manifestation of an invention that serves as evidence that an invention is already known. It is important to understand that prior art does not just refer to patented and commercial products. Prior art also includes ideas available to the public, articles, publications, journals, a product available for sale, commercial use of an invention, presentations and demonstrations, and previously filed patents or patent

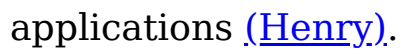




\section{Types of Prior Art Searches}

There are four major types of prior art searches:

1. Novelty search: This is usually conducted by the patent professionals before filing a patent application, and by the patent examiners during its prosecution (i.e., the interaction between the applicant and the patent office). These may be cursory and incomplete when conducted by the United States Patent and Trademark Office (PTO) and should not be relied upon for protection against future licensing, claims for invalidity, etc. While the pricing of searches varies depending on their complexity, it is safe to say that specialized patent law firms charge the least to conduct novelty searches.

2. Validity search: As the name suggests, this is conducted when a party seeks to validate (or invalidate) an issued patent. Since the objective here is to locate prior art that has been missed previously, these searches tend to be much more exhaustive. As a result, these are usually the most expensive searches when conducted by a third party.

3. Clearance (aka "freedom to operate") search: This is a search of issued patents to see if a given product (or process) violates another patent. This is typically done by businesses seeking to legally introduce a process or product without infringing on others' patent rights.

4. Landscape search: A landscape search is conducted to understand "current landscapes" while venturing into a new technological area. It is used for making strategic intellectual property (IP) and business decisions (see the chapter "Intellectual Property: Ownership and Protection in a University Setting." and "Intellectual Property: Commercializing in a University Setting"). These are priced between novelty and validity/invalidity searches.

For an academic entrepreneur who is also an inventor and looking to file a patent for their invention, the existence of a prior art has an impact on the patent's claim to originality and can thus render a claim in a patent invalid. Does this mean that if prior art exists and is relevant to an invention then a patent cannot be filed at all? No. Patentability does not hinge solely on the existence of prior art but rather on how different the invention is from the prior art.

\section{How to Conduct a Patent/Prior Art Search}

Technically, there is no legal mandate to conduct a patent/prior art search. Is it important? The reality is that it is a major concern and is constantly recommended by 
all patent offices, so that it can be determined by the inventor whether or not others have already staked a claim to that particular inventive concept before expending substantial efforts and expenses into the process of obtaining a patent.

There are firms that specialize in conducting patent searches, with a range of prices depending upon the type of search. Companies such as PlanetPatent (planetpatent.com) charge anywhere from $\$ 400$ for a simple novelty search to $\$ 800$ for a landscape search and up to $\$ 10,000$ for a validity/invalidity search, depending on the complexity of the search itself. Some firms also have an hourly patent search rate. There also exist low-budget patent search websites such as Patent Search International (patentsearchinternational.com) that charge $\$ 250 /$ search. Nevertheless, it is often more economical for the average academic entrepreneur to conduct their own preliminary patent searches, given the large array of resources that are publicly available and those that are available exclusively in an academic setting (see the chapter "Resources at Academic Entrepreneurship Centers"). It is also important to note that no search done by any set of professionals, including specialized patent search law firms, can be assumed to include all of the prior art out there: there is always a risk that some piece of art was missed during the search. In addition, an academic entrepreneur is likely the topic expert on the invention, which means they may have an exceptional understanding of terms of art, synonyms, and domains of knowledge pertaining to the invention that not even the most reputed patent firms have.

In his article "Three Keys to Ensure a Thorough Prior Art Search," Matthew McBride from the Chemical Abstracts Service (CAS) talks about the three keys to running a great prior art search: sources, scope, and query (McBride). According to this article, choosing the right source refers not only to patent databases but also to critical nonpatent sources such as journal articles, newsletters, and dissertations. Thus, a good way to broaden the scope of a patent search and also perform a smart patent search would be to explore databases that have both patent and non-patent sources. The searcher should also carefully define the scope of the search. For instance, a simple preliminary search may be sufficient at the start of a venture, but a more expanded search across different countries and landscapes will be required if the venture were to expand abroad. Once a database is chosen and a scope has been defined, the searcher then "asks the right questions." Keyword searches are a start, but as the search progresses, it may make sense to consider how the technology that is being queried has changed historically. If there are synonyms to the names used for the 
technology, is there any tangentially relevant information that is being missed out in the searches?

There are several resources available online to conduct patent/prior art searches, both public and paid. The publicly available resources are a great place to begin. One can either start off with rudimentary searches based on keywords and go through a large, exhaustive list of patents, determining each of their relevance and similarity to their invention, or they could filter choices and perform smart searches with codes and queries that result in fewer patents to look into. The method chosen can help focus the search and improve the level of detail and thoroughness desired.

Some of the popular publicly available resources are listed below (Krabbe et al.):

1. PTO: Patents (PATFT) - http://patft.uspto.gov/. This is a tool by the U.S. Patent and Trademark Office for Boolean and advanced Boolean searches of the U.S. patent fulltext and image database. It permits the performance of keyword searches and queries based on title, abstract, classification codes, dates, geographics, etc. It has an intuitive and user friendly interface for its query-based search engine.

2. PTO: Applications (APPFT)—http://appft.uspto.gov/netahtml/PTO/search-bool.html. Also by the USPTO, a tool for Boolean and advanced Boolean searches of the U.S. patent application full-text and image database. The usage and queries are the same as with PATFT since both these resources are provided by the PTO.

3. Google Patents-https://patents.google.com/._Google's relatively new patent search engine possesses the user-friendliness and comprehensiveness of Google searches to help streamline the daunting task of performing a patent/prior art search, especially for those new to the process.

4. Patent Cloud-https://app.patentcloud.com/index.html. This is a source with a helpful user interface that allows simple patent searches as well as advanced searches where the user can input patent type (utility patent, utility model, design, plant, others), patent status (application, issue), and what to search for in different subfields such as authors, abstracts, etc., in an intuitive manner. Patent searches are free, and premium account holders can search for designs, perform semantic searches, and utilize features like analytics, export options, and more. This "freemium" tool gives access to full database texts from the USA, the European Patent Office (EPO), the World Intellectual Property Organization (WIPO), Japan, China, Taiwan, and India, and access to abstract databases from over a hundred countries. 
5. Espacenet-https://worldwide.espacenet.com/singleLineSearch. The European Patent Office also owns the search engine called Espacenet, which contains published applications from over 100 countries and is an excellent resource for international patent searches. It allows one to conduct three kinds of searchessmart search, advanced search, and classification search-in English, French, and German. The resource contains simple links that guide one to perform queries. The tool also allows results to be exported in CSV and XLS formats.

6. Patentscope-https://patentscope.wipo.int/search/en/search.jsf. This is owned by the World Intellectual Property Organization and is structurally similar to the abovediscussed resources but functionally different in the fact that it provides access to international patent documents. Patentscope also has a lot of unique and interesting features, such as searching by chemical structure, a cross-lingual information retrieval that finds synonyms for keywords and translates them into multiple languages, a browse-by-week feature that allows one to browse weekly patent applications and analysis, and a sequence listing that contains nucleotide and amino acid sequences from the published work in the database.

An important note to keep in mind while exploring various prior art tools is the kind of information provided by each tool. Detail is essential in a patent search-every independent claim of every relevant patent needs to be analyzed. Thus, tools that provide aggregate-level data and beautiful graphs may please the eye but are not very useful for the practical purpose of conducting a patent search, as they tend to overly simplify the information.

The next step, after choosing a database or a search tool, would be to organize one's thoughts and channel them toward performing an efficient prior art search. The PTO provides a seven-step strategy for this (Public Information Services Group). A helpful, concise strategy is given below in Figure 1.

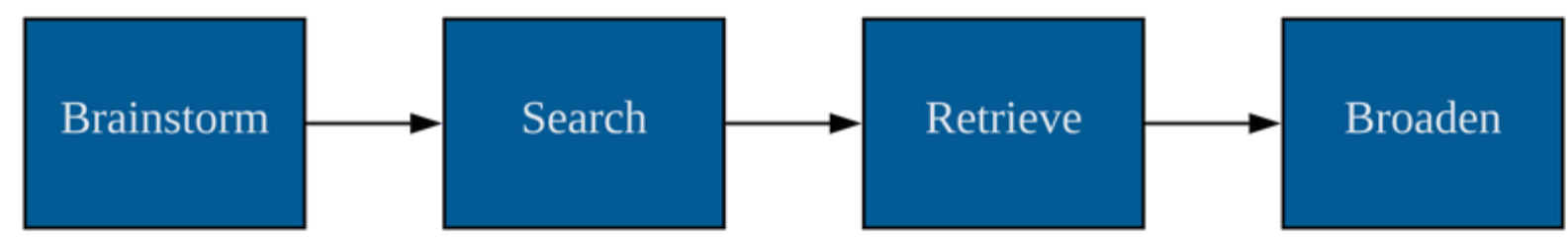

Figure 1

Search Strategy.

- Brainstorm terms that best describe an invention. 
- Search for these keywords to obtain relevant Cooperative Patent Classification codes (CPC codes) and verify the relevance of each one by reviewing the CPC classification definition, if available. This can be done on the USPTO website.

- Retrieve U.S. patent documents and U.S. patent applications using the CPC classification. This can be done in the websites identified by the first two resources listed earlier in this section.

- Broaden a search by using keywords instead of CPC codes and also by exploring non-U.S. patents from other resources.

Make sure that each of these searches is well documented as this may prove essential in later discussions with a patent lawyer or when filing paperwork to report to the patent office the prior art known by the applicant.

A prior art search can take anywhere between a couple of hours to a week or two. The time it takes depends to an extent on the kind of search and to an extent on the invention itself. For instance, a simple novelty search can take hardly any time in a well-explored space, especially because patent claims are generally very broadly phrased and hence an invention that resembles it can be rejected based on lack of novelty. Validity searches and infringement searches consume the most time, while clearance and landscape searches consume less time than validity searches. That said, perfection is the enemy of the good. There may be a point where the time allotted for the search has been spent and results attained are reasonably sufficient. A possible indication of a good prior art search is obtaining the same set of results through different channels, such as altering keywords, changing databases, searching for citations, searching author names, and searching for synonyms and technological jargon. If new results continue to pop up, they should be studied, and the current search methods should be analyzed and revisited until convergence and hence satisfaction with the search is attained.

\section{Example}

Let us try to carry out these steps with the help of an example. Suppose an academic entrepreneur is looking to patent the idea and process of using a transdermal patch that topically administers a vitamin E analog for the treatment of multiple sclerosis. In order to file a patent, the first step is to perform preliminary prior art searches to make sure that the application would not be deemed invalid.

The first step in this strategy is to brainstorm keywords-multiple sclerosis, vitamin E, and transdermal patch are some simple ones. As a whole, the product is a drug and a 
device. Let us consider just the drug aspect of the product for our illustration. Next, look these up in order to search for CPC codes. The following image is a screenshot of what the WIPO website looks like Figure 2(World Intellectual Property Association (WIPO).).

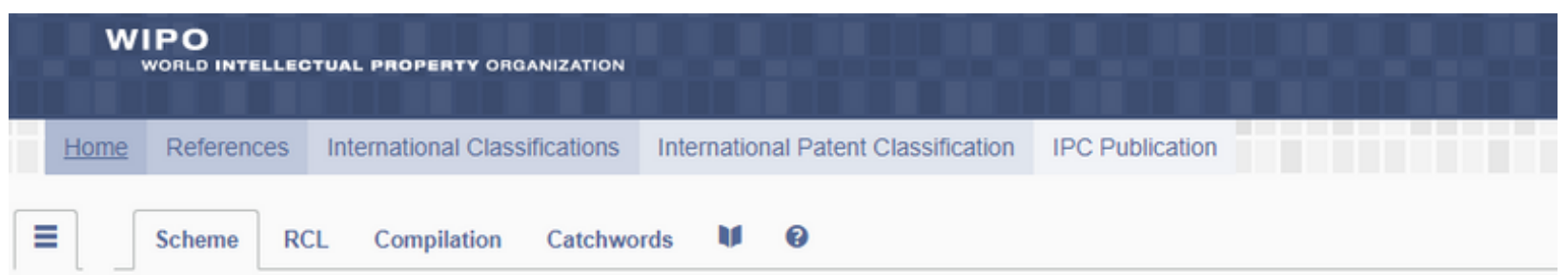

\begin{tabular}{|c|c|}
\hline A & HUMAN NECESSITIES \\
\hline B & PERFORMING OPERATIONS; TRANSPORTING \\
\hline c & CHEMISTRY; METALLURGY \\
\hline D & TEXTILES; PAPER \\
\hline E & FIXED CONSTRUCTIONS \\
\hline $\mathbf{F}$ & MECHANICAL ENGINEERING; LIGHTING; HEATING; WEAPONS; BLASTING \\
\hline G & PHYSICS \\
\hline H & ELECTRICITY \\
\hline
\end{tabular}

Figure 2 WIPO Sample.

A transdermal patch lies within the healthcare space, which would fall under "A: Human Necessities." Upon clicking on the plus sign to expand the subcategories under A, one can view a list ranging from agriculture to personal articles. We are interested in medical/veterinary science, which is A61 and falls under the subcategory "Health; Life-Saving; Amusement." Click on A61 to expand it further.

The transdermal patch, which is a drug-device product, would logically fall under A61K: "Preparations for medical, dental, or toilet purposes" (read the descriptions and select what is most suitable). Expand this. Now, we should brainstorm keywords: the drug is a vitamin E analog, which means that we should be looking for the category of compounds that vitamin E falls under, and this category would in turn fall under the super-category of organic compounds. Browsing through the expanded list with this in mind, we then locate A61K 31/00: "Medicinal preparations containing organic active ingredients" (Figure 3 and Figure 4). 


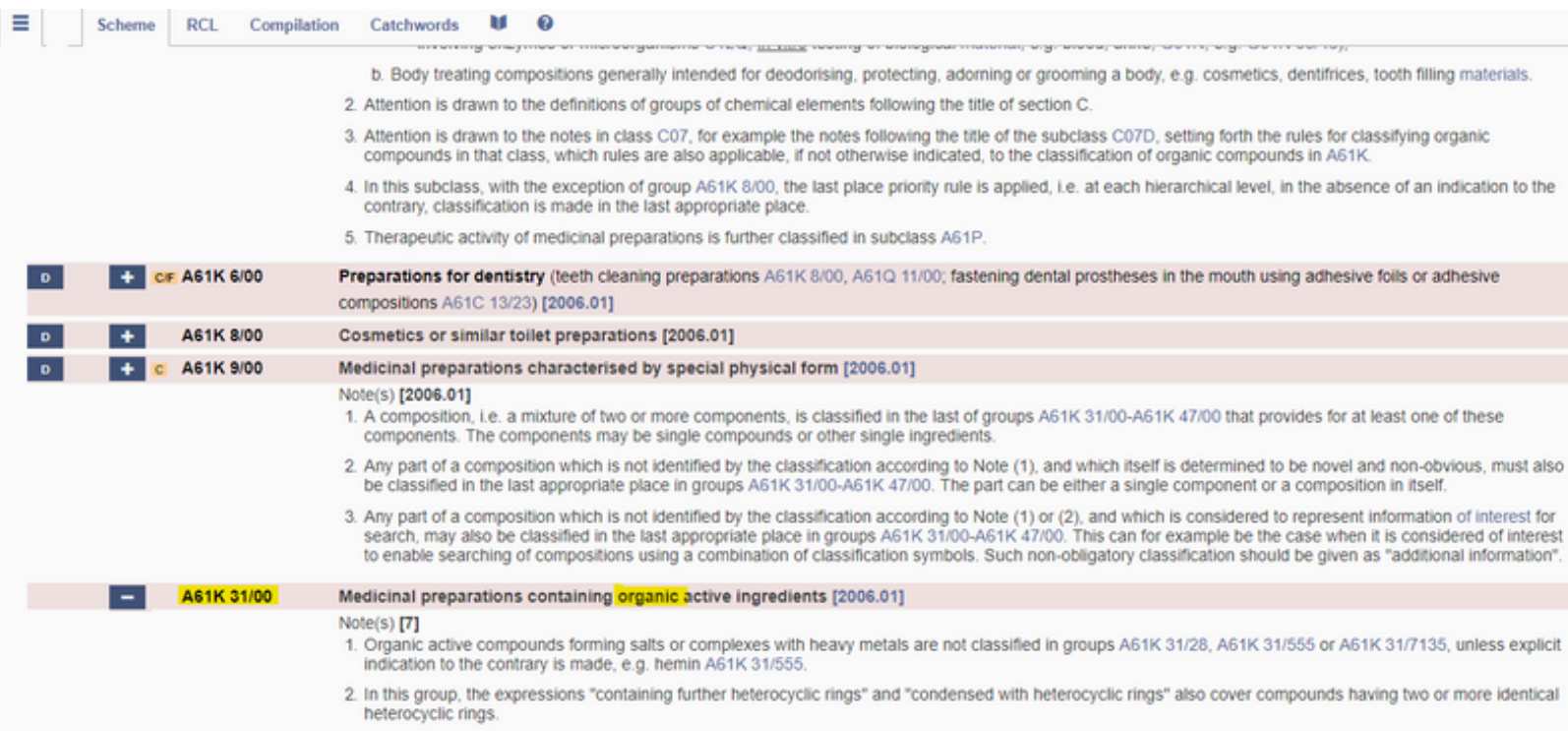

1. Organic active compounds forming salts or complexes with heavy metals are not classifed in groups A61K 31/28, A61K $31 / 555$ or A61K $31 / 7135$, unless explicit indication to the contrary is made, e.g. hemin A61K $31 / 555$.

2 In this group, the expressions "containing further heterocyclic rings" and "condensed with heterocyclic rings" atso cover compounds having two or more identical heterocyclic rings

Figure 3

Initial Search Results.

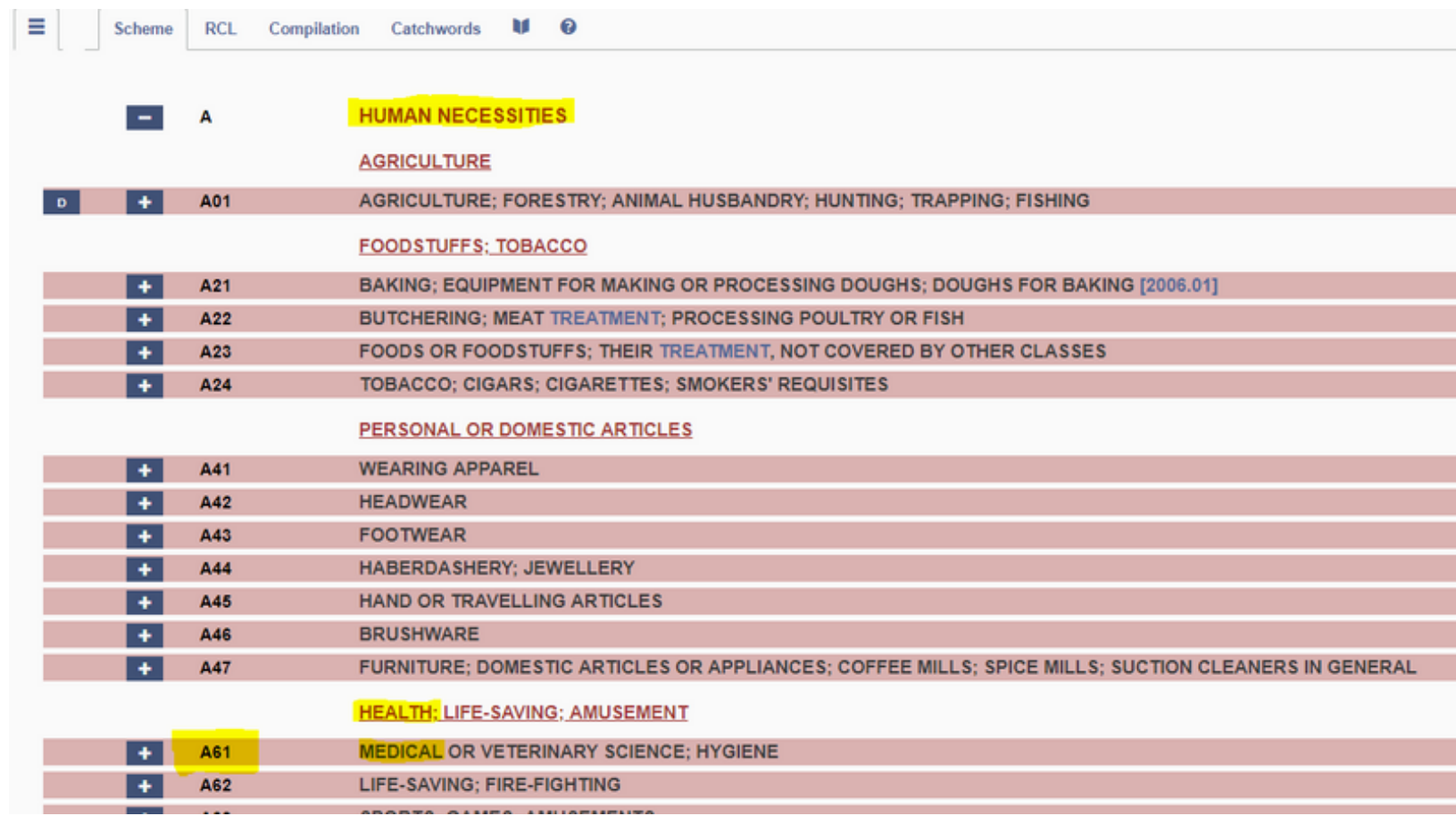

Figure 4

Expanded List.

Next, we look for the chemical name of the category of vitamin E (or simply press CTRL+F and search for "vitamin E" on the page). This leads us to a candidate CPC code. 
Copy this CPC code and search for patents and patent applications on the PATFT and APPFT websites. The search can be further refined by adding a Boolean statement "AND multiple sclerosis." Now go through each one of the patents and patent applications and check for relevance and similarities with the product.

Once finished with the refined searches, begin expanding the search by playing around with the key words and also exploring other databases (international databases, patent websites of other countries, etc.), working to make the searches as reasonably comprehensive as possible.

\section{Obtaining Expert Counsel}

In case guidance is needed, resources from affiliated universities can always be sought for counsel. There are several people who are trained to be domain experts in prior art searches and will be more than willing to help out, especially in the technology transfer office (see the chapter "Working with the University Technology Transfer Office"). Additionally, there may even be law school classes that focus on patents, which could take up such cases as a class project. Many law professors, patent lawyers, and general experts in the domain also write blogs that are a rich source of tips and tricks on how to conduct prior art searches. There are many a time when an inventor's judgment can be biased toward their invention being unique while searching for prior art. Or they may choose not to disclose the discovery of a certain prior art because they do not feel it is similar enough. During such cases, obtaining expert counsel, be it an attorney who gets paid by the hour or a librarian at the university who specializes in conducting and analyzing prior art searches, can be a boon to mitigate such biases.

\section{Resources}

U.S. Patent Full-Text Database Boolean Search.

U.S. Published Application Full-Text Database Boolean Search.

Prior Art: Types of Searches.

Seven Step Strategy_(Public Information Services Group).

Google Patents.

$\underline{\text { WIPO-Search International and National Patent Collections. }}$ 
Espacenet: Smart Search.

Patentcloud: Patent Search Insights for Impactful Decisions.

The contents of this chapter represent the opinions of the chapter authors and editors. The contents should not be construed as legal advice. The contents do not necessarily represent the official views of any affiliated organizations, partner organizations, or sponsors. For programs or organizations mentioned in this chapter, the authors encourage the reader to directly contact the relevant organization for additional information.

\section{Citations}

1. Henry, Michael. "What Is Prior Art?” Henry Patent Firm, 7 Sept. 2017, https://www.henry.patentfirm.com/blog/what-is-prior-art. $\triangleq$

2. McBride, Matthew. Three Keys to Ensure a Thorough Prior Art Search. American Chemical Society / CAS, pp. 15-17, https://www.cas.org/sites/default/files/CAS final_MarchApril.pdf.

3. Krabbe, Ellen, et al. "Patent Searching Using Free Search Tools." Intellectual Property Owners Association, 2017, http://www.ipo.org/wpcontent/uploads/2017/03/Free-Search-Tools-Bulletin -20170301.pdf..

4. Public Information Services Group. "Seven Step Strategy.” United States Patent and Trademark Office-An Agency of the Department of Commerce, https://www.uspto.gov/learning-and-resources/support-centers/patent-and-trademarkresource-centers-ptrc/resources/seven. Accessed 15 Aug. 2019.

5. World Intellectual Property Association (WIPO). IPC Publication. https://www.wipo.int/classifications/ipc/ipcpub/?

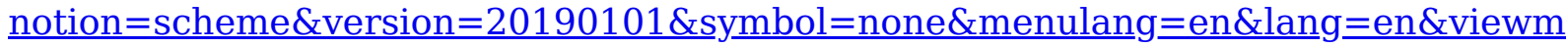
$\underline{\text { ode }=f \& \text { fip }} \underline{p} \underline{c}=$ no\&showdeleted $=y$ es\&indexes =no\&headings $=y$ es\&notes =yes\&direct

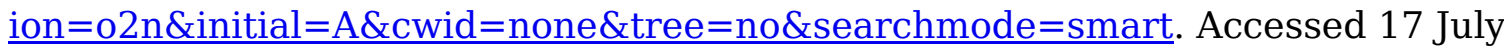
2019. 